Article

\title{
Sustainability Driven by Agriculture through Digital Transformation
}

\author{
Larisa Hrustek (D)
}

Faculty of Organization and Informatics, University of Zagreb, 42000 Varazdin, Croatia; lhrustek@foi.unizg.hr; Tel.: +385-99-678-1862

Received: 29 September 2020; Accepted: 15 October 2020; Published: 16 October 2020

\begin{abstract}
Economic, environmental and social sustainability is increasingly gaining the attention of academia and commitment in the policies of national economies. Global warming and climate change, weather disasters and disruptions are just some of the challenges that can drastically disrupt stable business models, and thus jeopardize sustainability. Agriculture, as an activity at the center of the value chain, is facing these problems, and, at the same time, contributes to feeding the growing world population and is responsible for conserving resources and ensuring sustainability. Process automation, data analysis and processing, control and management of agricultural operations have transformed the agricultural business and contributed to sustainability, survival and development within supply chains. This article analyzes the literature in the field of sustainability and agriculture led by digital technologies of Industry 4.0. The analysis of the research field showed the high importance of the topic in academic and national circles, given the number of published articles. Secondly, the concepts of sustainable agriculture and sustainability driven agriculture in the context of digital transformation were analyzed and it was shown that transformed agriculture can successfully cope with today's challenges. Finally, guidelines for sustainable development driven by agriculture through the determinants of digital transformation are defined.
\end{abstract}

Keywords: sustainability; agriculture; digital transformation

\section{Introduction}

We live in an age when new-generation digital technologies have become an integral part of all spheres of human life and an unavoidable backbone of the business. Big data, robotics, artificial intelligence, virtual and augmented reality, the Internet of Things, Blockchain, adaptive systems, bio and neurotechnology have long ceased to be new, but have moved into the category of technologies we must learn to manage competently [1], and with their help tackle today's challenging problems such as global warming, climate change and economic disruption. These challenges cause disruption and pose a threat to the concepts of economic, environmental and social sustainability. The first of the priorities of ensuring the sustainable development of the global economy is related to ensuring stability, i.e., enabling the prevention of the increase in the frequency of cyclical fluctuations and new global crises. The second priority is the ability to ensure a high rate of economic growth and to maintain a balance of economic progress and a favorable environment for the prevention of environmental crises [2]. In order to effectively overcome the challenges and achieve the goals of the concepts of sustainable development, organizations and disruptors around the world must understand the key drivers of digital transformation that affect their business and industry [3]. Digital transformation enables the continuation of the process of human social development and the economic development of countries. This improves the life quality of billions of people, which is achieved through the fair distribution of all benefits, protection from inevitable negative effects and ensuring the expansion, not limitation, of the capabilities of all the country's inhabitants [1]. Agriculture, industry, services, 
and innovation [2], driven by digital technologies, are mentioned as four key determinants of global economic growth. Today, agriculture is seen as an integral part of the value chains at the heart of our economies, providing invaluable services to society [4,5], ensuring food security, stability and strengthening countries' economies [6], and its growth focuses on economic, environmental and social sustainability [7], where compliance with an increasing number of environmental and quality regulations is expected [6]. Advances in technology have changed our diet and eating habits, lifestyle, our perception and understanding of some environmental issues [8], so agriculture is directly related to these assumptions.

There are several reasons why in the future it will be very important for agriculture to be digitally transformed and thus ensure not only the sustainability of the agriculture business individually but also the economic, environmental and social sustainability of society as a whole. Based on the FAO's (Food and Agriculture Organization) 2018 prediction, the world's population will number around ten billion by 2050, with significant regional differences in economic growth. At the same time, food production is a major challenge that will be further exacerbated by climate change, reduced water supply and the environmental impacts of intensive plant and livestock production. The FAO recommends the adoption of digital technologies to increase productivity and address food safety risks (2017) [9].

In the agricultural sector, digital technologies affect the entire value chain, from suppliers of input products to consumers [10], and close links with other industries require an innovative, adaptable and competitive way of doing business [11]. Current practice has been marked by smart and precise agriculture and its application can be distinguished through four forms of practice $[1,11,12]$. These are process automation and robotics, agricultural applications and information systems, cyber-physical systems, related tools and machines, and collection and analysis of large amounts of data. So far, attention has been focused on the sustainability of agriculture by achieving the goals of flexibility and efficiency through agricultural processes. In the future, the digital transformation of agriculture should provide an answer to all the challenges of today and facilitate the struggle.

First, through digital transformation, agriculture should become an attractive activity on the market, with wide opportunities for the development of new agricultural enterprises and the creation of new jobs and improving the competitiveness of agricultural holdings, i.e., economic sustainability. Second, the impact of the consequences of climate change, habitat change and increasingly frequent weather disasters can be controlled with precision agricultural systems through pesticide control, reducing water use and ensuring environmental sustainability. Third, digital technologies in agriculture would contribute to the development of rural areas and poor regions, thus enabling social sustainability. The transformation of agriculture would result in a sector that cooperates with other industries [5] and through its activities ensures sustainable development and provides resistance in the fight against all challenges. The concept of this smart, precise and strengthened agriculture is linked to at least five sustainable development goals of the United Nations such as decent work and economic growth, industry, innovation and infrastructure, sustainable cities and communities, responsible consumption and production, and climate action [10].

This paper should provide an overview and answers to the following research questions:

- What is the current state of research on sustainability, agriculture and digital transformation?

- What does sustainable agriculture mean in relation to sustainability driven by agriculture in the context of digital transformation?

- What are the assumptions for the development potential of agriculture in the direction of sustainable development at the economic, environmental and social levels in the context of digital transformation?

- What are the expectations at the level of economic, environmental, and social sustainability driven by transformed agriculture?

One of the aims of this paper is to show the growing importance of the concept of sustainability in science, policies, economies and to identify the role of agriculture, supported by the determinants 
of digital transformation, as a key activity in the development of sustainability. On the one hand, more and more frequent challenges to agricultural business systems have been identified, while on the other hand, as a priority of policies and actions, the fulfillment of requirements for ensuring economic, environmental and social sustainability is expected. The link between challenges and requirements is the digital transformation as a paradigm that determines the transformation of agricultural activities and processes through determinants. The second goal of this paper is to point out clear differences in the role and perspectives of agriculture in terms of the concept of sustainability, currently and in the future, through the context of digital transformation. In particular, the goal is to show the differences through the key determinants of digital transformation, which include digital technologies and infrastructure, strategic orientation, innovation, organizational culture, capacity and customer-centricity. The emphasis was placed on recognizing the different perspectives of agriculture in the concept of sustainability, which is currently limited to the sustainability of the agricultural holding, and the forthcoming period indicates a changed role and perspective of agriculture. Agriculture will become an activity that, through its transformation and future actions, will enable the simultaneous struggle with challenges, on the one hand, and the realization of the set requirements related to the concepts of sustainability, on the other hand. The third goal is to define guidelines for the implementation of activities and tasks in agriculture as an activity that leads to economically, environmentally, and socially sustainable growth and development. Ultimately, the aim of this paper is to point out the positive effects and expectations at the level of economic, environmental, and social sustainability, driven and achieved by transformed agriculture. Namely, the idea is to identify and define potential scenarios that will result in sustainability driven by agriculture in the future.

In this paper, the methodology of the conducted research will be presented first, and the current situation on the research topic will be analyzed through a review of the literature. Furthermore, the results of the research will be presented in the following chapters. First, there will be an explanation of the differences between sustainable agriculture and agriculture that leads to the economic, environmental and social sustainability of what is known as sustainability driven by agriculture. Next, a discussion will be opened with several new assumptions about the development potential of agriculture in the direction of sustainable development and guidelines for achieving sustainability with the help of agriculture. In addition, some of the potential scenarios based on sustainability driven by agriculture will be defined. At the end of the paper, the topic will be concluded.

\section{Methodology}

The research started based on a complex query: "agriculture" AND "sustainability" OR "sustainable agriculture" AND "digital transformation" OR "digital technologies" OR "Industry 4.0 ", and the relevant databases Scopus and platform Web of Science were searched. The mentioned complex query, in the selected databases, was searched by topic, i.e., the title, abstract, and keywords were included in the search. Given the results obtained, i.e., the number of articles on the topic and the year of publication, there were no special restrictions in this search. This search was done to provide insight into a research field that includes sustainability and agriculture in the context of Industry 4.0 technologies and digital transformation. The aim of this research is to identify and define trends that will characterize sustainable growth and development through the agriculture business, based on the determinants of digital transformation. The literature review and the results of the conducted analysis will be presented below.

\section{Literature Review}

The current state of the scientific literature on Industry 4.0 and the use of digital technologies in agriculture, as well as the determinants of digital transformation and their status in the context of the agricultural field, will be defined below. 


\subsection{Agriculture 4.0 and Precise Agriculture}

The introduction of digital technologies in agricultural processes and changes in the way of working are considered to be the fourth revolution in agriculture $[8,11,13]$. The concept of Agriculture 4.0 originated from the concept of Industry 4.0 and refers to the adoption of digital technologies to create a value chain that integrates the organization, customers, and other stakeholders [13]. In recent years, great emphasis has been placed on precision and smart agriculture. Precision agriculture is a discipline characterized by the collection, storage, processing, and sharing of digital data from various sources with clearly defined objectives [9], while smart agriculture involves the implementation of software systems with integrated digital components, which support the conversion of raw data into useful information for agricultural activity and approaches to work [12]. The main technical requirements of precise and smart agriculture are data harmonization, friendly user interfaces, simple methods for executing algorithms, and simple methods for applying new methodologies, interoperability between systems, scalability, and support for metadata [9].

Industry 4.0 and precision agriculture have many common goals. Most important are process digitization, robotics and process automation, hyper-connectivity and processing of large amounts of data and machine learning [12]. The authors agreed with a similar distribution, dividing the typology of digital technologies for agriculture in a slightly different way, but they can actually be interpreted in the same or a similar way. The four groups of these technologies are (a) agricultural knowledge and information systems, (b) tools and services that provide market access and market opportunities, (c) automation of business processes in various forms of management, (d) automation of the process of ensuring food safety in the region [1].

All of the above represents a major step forward in agriculture as an activity that must face the challenges of productivity and sustainability [3]. However, the current situation is far from ideal and the agricultural sector is not only unattractive in society, but its role and importance within economic systems and value chains has been neglected. On the other hand, the potential of this sector is huge. Agriculture can no longer be seen as an activity that needs to be made sustainable, but as the backbone on which ecological, economic and social sustainability will be based. A strategic approach, capacities, digital technologies, customer centricity, organizational culture and innovation will play an important role in this, and one of the main resources will be digital data, which is recognized as a major factor in agricultural production. However, the creation of single information space for agriculture, and thus for agricultural science, is still open [1].

\subsection{Digital Technologies in Agriculture}

Industry 4.0 marked agricultural activity through the integration of cyber-physical systems, Internet of Things technologies, Artificial Intelligence and Machine Learning, Big Data and Analytics, and Cloud technology with agricultural machinery [14-16]. Cyber-physical systems are important for the development of innovative solutions for monitoring and managing processes in agricultural enterprises, and industrial Internet of Things components such as sensors and cloud computing are used to monitor soil parameters and weather conditions to enable smart irrigation solutions, and control insect attacks and pesticide use. The importance of big data and machine learning contributes to data understanding, crop management systems in livestock and water management. Fleets of drones and ground vehicles are used to reduce pesticides thanks to real-time detection systems, and smart agricultural tools have the role of precise real-time handling. The combination of drones and smart glasses make it possible to take advantage of augmented reality to monitor and sample cultivated soils to identify and manage a possible critical area [15]. Sensors and smart applications are important for monitoring the occurrence of unexpected events and conditions that could eventually affect potential risks, such as the impact on the perishability of the flow of food products through the supply network [17].

The possibilities of digital technologies have an influence on changes in the way a number of agricultural activities operate through the adoption of new business models. There is indeed a 
large number of adopted models through which farmers can increase production, optimize resource consumption (including labor), costs, and quantitative and qualitative production opportunities, in line with the specifics of production [15].

The most adopted are object identification, georeferencing, measurement of physical and chemical parameters, satellite navigation, connectivity, data storage and analysis, process automation and vehicle driving [15]. Some of the other scenarios covered by digital technologies in agriculture are sensor greenhouse management, energy efficiency, observation of phenological phases, detection of insects or crop diseases, traceability of the production chain, irrigation planning, optimization of plant growth, monitoring of agricultural land and agricultural land management [14].

Some of the technological solutions that will contribute to sustainability through agriculture in the coming period are definitely blockchain technologies for greater transparency and food safety, advanced genetics, controlled environmental agriculture and vertical farms, biotechnology, including microbiome management, biological soil agents, farmed meat, and replacement proteins for meat and dairy products. 3D printing technology will enable the production of food and tasty plant-based substitutes through technology. In addition to opportunities to start and develop new businesses and services, this is crucial for environmental sustainability [3].

\subsection{Digital Transformation in Agriculture}

Digital transformation implies five key determinants through which digital maturity can be observed, namely strategic orientation, customer centricity, ICT and process infrastructure, talent, capability and capacity strengthening, innovation and organizational culture [18]. Digital technologies have a transformative impact on the global economy and society, and all efforts are focused on changing business models. This requires the preparation and implementation of digital strategies, in response to the spread of new digital technologies and the rise of new disruptive threats, and the adoption of an innovative and organizational culture and initiatives that exploit digital technologies to gain a competitive advantage. Some of these potential benefits are increased sales, productivity and customer-centered focus, resulting in innovations in value creation or new forms of customer interaction [3]. Digital transformation is inevitable in the needs of any business that strives for growth, expansion, quality, and sustainability [5,19].

Risk and uncertainty are unfortunately increasing, and climate change, limited availability and cost of resources, and market instability limit decision-making for both farmers and policymakers [3]. These changing trends lead to a new era in which digital technologies surpass human capabilities, even in tasks that do not follow the direct application of existing rules and were previously impossible to automate, such as those involving communication or pattern recognition in uncertain or changing environments [8]. Until now, the use of technologies in agriculture has been limited and focused on the sustainability of the agriculture business. Future research will be based on smart digital services that can help the agricultural industry meet the challenges of sustainability.

The exponential growth of computing capabilities is expected to result in faster cheapening and greater availability of smart solutions in the market, and by 2025, mobile Internet, knowledge automation, and the Internet of Things will have the potential to produce economic value of up to $\$ 33$ trillion a year worldwide. Renewable energy technology and advanced resource research will have an impact on the structure of revenues and expenditures, which can vary greatly [8]. The precision agriculture market expects growth of $15 \%$ by 2025 and it is estimated that revenue from the precision agriculture market will exceed the estimate of $\$ 12$ billion. The increasing application of smart agricultural practices accompanied by advances in management algorithms, big data, digital technologies and the integration of renewable energy systems will result in an increasing market. In addition, there are predictions that the segment of managed precision agriculture services will mark the progress of over $27 \%$ from 2019 to 2025 [6].

One of the aims of this paper is to show how agriculture plays an important role in ensuring sustainability through the determinants of digital transformation. The paper defines the characteristics 
of sustainability guided by agriculture in the context of existing determinants and emphasizes the difference with the existing characteristics of sustainable agriculture.

\subsection{The Concept of Sustainability in Policies}

Until now, the emphasis in agriculture has been on operational feasibility. The objectives of economic, environmental and social sustainability are often in conflict, and thus social expectations have not been met [4]. Today, through government actions and investments, it is very important to meet significant infrastructure requirements, take care to raise environmental awareness, and provide training to people about it. A significant challenge for agriculture towards sustainable development lies in ensuring more efficient agricultural processes at lower costs, providing safer and better working conditions for the environment and all stakeholders, and finally increasing synergies between them, offering the possibility to make decisions on issues that are usually beyond their reach $[16,20]$. Economic feasibility deals with income and expenditure and, in many cases, farmers may incur additional costs such as purchasing applications or software, equipping with smart solutions, etc. However, service providers may be able to subsidize applications and even technologies by helping with various aspects of sustainability and improving fair trade situations [10].

Sustainable development requires simultaneous consideration of economic, environmental, and social aspects, and a new business model for sustainable development called the circular economy helps to harmonize these aspects [21]. For the period 2021-2027, the European Commission has proposed an agricultural policy based on nine key objectives, which are to ensure a fair income to farmers, to increase competitiveness, to rebalance the power in the food chain, climate change action, environmental care, to preserve landscapes and biodiversity, to support generational renewal and vibrant rural areas, and to protect food and health quality [22]. These goals are the basis for the development of strategic plans for the development of agriculture based on digital technologies and the transformation of this sector. The focus of the goals on social, environmental, and economic issues has given a clear signal that it is necessary to build sustainability driven by agriculture (Figure 1).

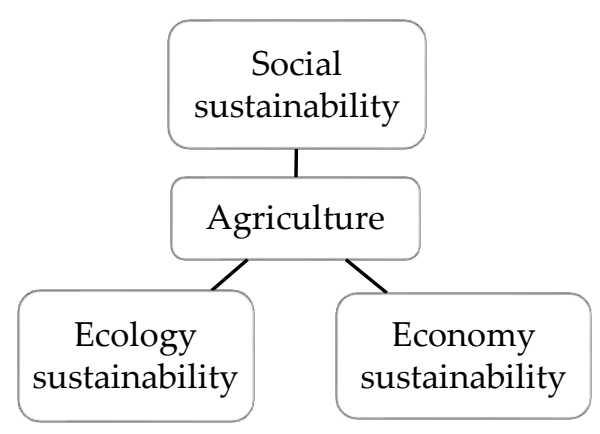

Figure 1. Sustainability driven by agriculture.

Social sustainability in the context of agriculture means providing food for all people in the world and for all animal and plant species. It actually involves a lot more than that. One of the important aspects of social sustainability is food safety and control due to the importance of production of healthy food. Ecological sustainability includes care for the environment and the protection of the biodiversity of nature and animals. The role of agriculture in this segment is crucial and there is a huge need to develop technological solutions that will enable smart management of agricultural production in terms of reducing the use of pesticides, herbicides, and fertilizers, then reducing emissions and more. Ultimately, economic sustainability is closely linked to the current viability of the agricultural business, and the revenues and profits generated. Namely, today agricultural holdings strive for mass production in order to generate as much income as possible because it is not possible to operate at a profit through small production quantities. A big problem is the low price of agricultural products 
for direct producers on the market, and at the same time, their uncompetitive position on the world market prevents them from fighting for their own income.

The future period will mark the sustainability of the entire supply chain, where agriculture has the goal of the development, implementation, and adoption of digital solutions in all business processes whose application results in high quality and safety of food and feed, while ensuring efficient, environmentally friendly and sustainable business.

\section{Results}

The results of this research will be presented below in response to the research questions asked. First, the results and current status of the research field will be displayed, with an emphasis on the number of articles published. Furthermore, the differences between the concepts of sustainable agriculture and sustainability driven by agriculture in the context of digital transformation will be defined. Finally, there will be an emphasis on assumptions and guidelines on the development potential of agriculture in the direction of economic, environmental and socially sustainable development.

\subsection{State of the Art}

As a result of the search for the complex query "agriculture" AND "sustainability" OR "sustainable agriculture" AND "digital transformation" OR "digital technologies" OR "Industry 4.0" in the Scopus database, it was found that 34 articles and 31 articles were available for analysis. The same search of the WoS platform resulted in 23 articles. After reviewing the articles, it was found that out of 23 articles from WoS, 15 of them were compatible with articles from Scopus, and the other 8 differed, of which 1 article was not available for analysis. This resulted in a total of 42 articles for further analysis, of which 38 were available (Table 1 ).

Table 1. Number of articles published in Scopus and Web of Science.

\begin{tabular}{cccc}
\hline Database/Platform & Scopus & WoS \\
\hline Number of articles & 34 & & 23 \\
Number of articles without matching & & 42 & \\
Number of available articles & & 38 & \\
\hline
\end{tabular}

Figure 2 shows the intensity of article publications over the years in Scopus and WoS. The obtained result on the defined query showed that the articles were published from 2014 onwards. A very small number of articles were published by the end of 2018; only 11 of them were found, after compatible articles were identified. In 2019 and 2020, the number of published articles increased compared to previous years, and a total of 31 articles were published, after the identification of compatible articles, which shows the growing importance of this area of research. Given the results of the analysis, the area that connects Industry 4.0 and agriculture and their impact on sustainability will certainly be a hot topic in the scientific and social community in the coming period.

\subsection{Sustainable Agriculture vs. Sustainability Driven by Agriculture}

This chapter will explain agricultural sustainability and sustainability driven by agriculture in the context of digital transformation. Namely, the notion of sustainability in the field of agriculture is increasingly mentioned, but nowhere is the significant difference between these two terms explained and emphasized. Sustainable agriculture is certainly a topic that has marked the period so far and has been the main focus of the implementation of digital technologies in agriculture. In the coming period, great attention will be paid to achieving economic, environmental, and social sustainability driven by agriculture based on key determinants of digital transformation. Interest in this area has not only increased in the scientific community but also the policies of the European Union created for the coming period have placed great emphasis on this area. 


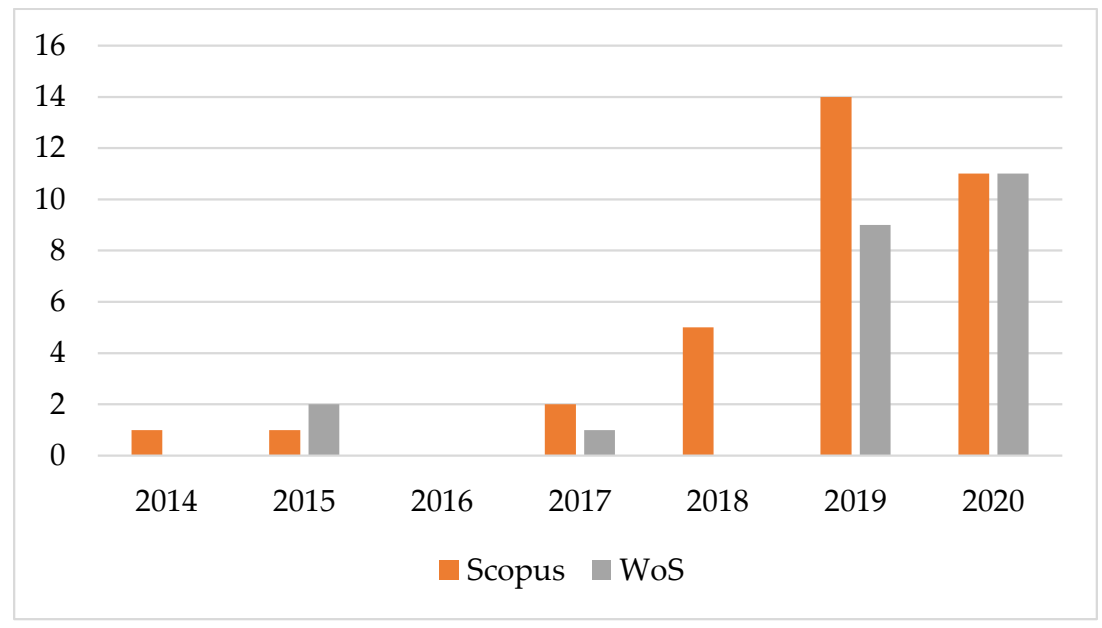

Figure 2. Number of articles published in Scopus and WoS by year.

The already mentioned precision agriculture is a technological innovation that can potentially improve the efficiency and sustainability of agriculture [12]. Sustainability and resource management in the agri-food sector as key research topics have marked science in the context of management, considering global population growth and increased food needs, while on the other hand there is social and organizational competition, scarce natural resources [17], climate change and disruptions.

The problem with sustainable agriculture is the focus exclusively on the operation of the agricultural business. Namely, sustainability has so far been viewed in a different context within the supply chain perspective [17], where the aim was to ensure the sustainability of the agricultural business by achieving efficiency and effectiveness of business processes. The digital transformation of the agricultural sector was supposed to ensure greater flexibility, efficiency, effectiveness and automate processes, ensure savings and enable faster decision-making, which contributed to the sustainability of agricultural business. Innovative business models in agriculture have been marked by precisely these goals.

Concerns about sustainability have led to thinking and focusing on the development of innovative business models, supported by digital technologies, aimed at improving supply chains [23], with agriculture at the center [4]. Increasingly, science is focusing on identifying the data needed to conduct modeling and analysis so that stakeholders can make decisions about managing natural resources to promote sustainability. Sustainability driven by agriculture should allow for greater reactivity and resilience, and thus increase safety. For example, agriculture has a strong impact on water resources, as the sector consumes and pollutes almost $70 \%$ of global water reserves. Digital transformation in water supply networks through sensor-driven operations could help promote eco-sustainability. In addition, a major problem is the biological nature of food products and food waste; traceability and transformation through real-time monitoring of distribution and storage conditions, and monitoring the effects of food quality and deterioration through sensory applications, could further boost consumer confidence [17].

Economies and governments around the world are actively developing policies to support and grow their supply chains, thus increasing society's expectations regarding agricultural services and performance. Agriculture is expected to be an activity to meet food needs and at the same time nurture the characteristics of a sustainable economy with satisfactory incomes, but it must also nurture an important role in value chains that provide raw materials incorporated or converted into animal feed, fiber, fuel, medicines, and other industrial products. At the same time, they are expected to maintain and preserve nature, so their agricultural practices must be economically, ecologically, and socially sustainable and in line with the broader and changing values of our societies [4]. It is inevitable to mention difficult and unpredictable working conditions such as climate change, more frequent weather disasters, and disruptions that require great flexibility in agricultural business. 
So, the emphasis is no longer on the sustainable agriculture, but we are talking about sustainability driven by agriculture. Below is a Table 2 that explains the difference between these two concepts through the determinants of digital transformation.

Table 2. Overview of differences between sustainable agricultural and sustainability driven by agriculture in the context of digital transformation.

\begin{tabular}{|c|c|c|}
\hline & Sustainable Agriculture & Sustainability Driven by Agriculture \\
\hline Strategy orientation & $\begin{array}{l}\text { Focus on the performance of the } \\
\text { agricultural enterprise productivity } \\
\text { and efficiency. } \\
\text { Market value and market share. }\end{array}$ & $\begin{array}{c}\text { Smart digital strategy [24]. } \\
\text { Focus on reducing the biological diversity of } \\
\text { the planets [2]. } \\
\text { Harmonization of economic, environmental and } \\
\text { social objectives [4,25]. } \\
\text { Focus on the creation and adoption of agriculture } \\
\text { innovations [12]. } \\
\text { Focus on strengths in addressing weaknesses } \\
\text { exacerbated by external threats [24]. } \\
\text { Co-financing of smart solutions [10]. }\end{array}$ \\
\hline Customer centricity & $\begin{array}{l}\text { Customer needs are at the center of } \\
\text { communication with customers. }\end{array}$ & $\begin{array}{l}\text { Ecosystem of customers, farmers and } \\
\text { other stakeholders. } \\
\text { Involving customers in activities } \\
\text { the needs of all stakeholders are essential. }\end{array}$ \\
\hline ICT and process infrastructure & $\begin{array}{l}\text { Implementation of digital technologies. } \\
\text { Technological solutions for individual } \\
\text { business processes. }\end{array}$ & $\begin{array}{l}\text { Taking advantage of all the benefits of technology } \\
\text { Technologies for food production and food } \\
\text { safety control [4]. } \\
\text { Improved algorithms created through the } \\
\text { analysis of existing data from business processes } \\
\text { and open digital data on weather conditions, } \\
\text { spatial or other [14] } \\
\text { technologies for control of resource } \\
\text { consumption [17,26]. } \\
\text { Tools for controlling activities in the entire } \\
\text { value chain [23]. } \\
\text { Interoperability of services and related data [9]. }\end{array}$ \\
\hline $\begin{array}{l}\text { Talent, capability and capacity } \\
\text { strengthening }\end{array}$ & $\begin{array}{l}\text { The main resource is the data collected. } \\
\text { The competitive advantage is the } \\
\text { application of digital technologies. } \\
\text { Knowledge and skills are limited to the } \\
\text { use of digital technologies. }\end{array}$ & $\begin{array}{l}\text { The main resource is new agricultural knowledge } \\
\text { and algorithms. } \\
\text { Competitive advantage is sustainable } \\
\text { technology-driven growth and development. } \\
\text { Knowledge and skills combine the use of digital } \\
\text { technologies, agricultural science and science of } \\
\text { other related sectors with the concepts of } \\
\text { sustainability and a multidisciplinary approach. }\end{array}$ \\
\hline $\begin{array}{l}\text { Innovation culture and } \\
\text { organizational commitment }\end{array}$ & $\begin{array}{l}\text { Creation of innovation in agricultural } \\
\text { products or services. } \\
\text { Creation of innovation in individual } \\
\text { agricultural business processes. }\end{array}$ & $\begin{array}{l}\text { Creation and adoption of innovations in } \\
\text { agricultural products and production and digital } \\
\text { innovation [12]. } \\
\text { Development of technologies for support and } \\
\text { education on innovations [12]. }\end{array}$ \\
\hline
\end{tabular}

Table 2 shows the characteristics of the determinants of the digital transformation for sustainable agriculture and sustainability driven by agriculture. These two concepts, seemingly similar, focus on sustainability in different contexts. The notion of sustainable agriculture has marked a period in agriculture so far, along with precision and smart agriculture. The aim was to ensure the sustainability of the agricultural holding through the application of technological solutions that were limited to individual business processes. Data were collected and represented the main resource whose role was mainly of informative importance. Agriculture business dealt exclusively with communication with customers, and innovations were limited to product or production innovation.

Sustainability driven by agriculture has some other, more advanced features of the determinants of digital transformation that combine the economic, environmental, and social concept of sustainability. The strategic orientation of policies and plans is aimed at ensuring and harmonizing sustainability goals. For example, some of the strategic plans are to protect land biodiversity, reduce the negative effects caused by agricultural production such as gas emissions, the use of pesticides, herbicides, and fertilizers, and increase the savings of resources such as water. In addition, support for innovation and development 
is also an important aspect of developing sustainable agricultural practices. Focusing not only on the customer but on all stakeholders in the value chain is very important to ensure sustainability, especially social. Meeting the needs of everyone in the value chain and contributing to the achievement of individual goals is very important for the survival of the market, especially in times of frequent disruptions that disrupt normal economic and social flows. Meeting infrastructure requirements and the use of digital technologies that connect all processes, and in the background of which advanced algorithms have been developed for specific agricultural processes, will mark the future and will play a very important role in ensuring sustainability. Of particular importance will be solutions developed to ensure sustainability, such as applications or software that save resources, and control the processes of protection, irrigation, control, safety, and consumption in agricultural processes. Talent, ability, and capacity building will be related to the discovery of new data, linking and using agricultural data from different sources, and creating advanced algorithms and knowledge that contribute to the sustainability of the economy, but also social, economic, and environmental sustainability. In addition, great attention will be paid to the multidisciplinary approach and the acquisition of skills in agricultural business. Innovations and organizational culture will be focused on the development of new innovative forms of business and cooperation and the creation of a culture of learning and development. Great emphasis will be on sharing data and knowledge and creating new products and services, innovative and improved processes, and forms of cooperation through platforms or smart tools.

\subsection{Guidelines for Sustainable Development through Agriculture}

This chapter provides an overview of sustainability driven by agriculture through the characteristics of the determinants of digital transformation. The features are explained with an emphasis on the opportunities they bring for sustainable development.

\subsubsection{Strategy for Sustainable Development Driven by Agriculture}

Environmental sustainability and biodiversity are expected to be reduced through sustainability driven by agriculture. Namely, agricultural activity and the food sector are responsible for about 19-29\% of global gas emissions Through a strategic approach to the exploitability of digital technologies, in terms of developing solutions such as data management, automation, traceability, better working conditions and the reduction in chemicals, environmental protection and biodiversity will be enabled [2], and strategy creators are in charge of their policy and strategy implementation. Therefore, a much clearer understanding of the roles and responsibilities that governments, industry, agriculture and consumers have in achieving the objectives of the concept of sustainability is needed [4]. In a changing environment like the current one, farmers should emphasize their strengths by using digital technologies and get rid of their weaknesses, always faced with external threats [4].

A smart digital strategy involves the integration and collaboration of all operations in the value chain, from buying to selling and after selling. The generated data is managed and used and applied to real-time responses through which they are able to understand and anticipate the needs of their customers, personalizing products and services. Through IoT, Blockchain, AI and activity automation, a timely response to disturbances is achieved [24].

\subsubsection{Stakeholder Focus in Sustainable Development}

Creating value to meet the new requirements of customers, stakeholders, and manufacturers through joint activities and cooperation is manifested in the form of joint innovations, including business model and technological innovation. Digital technologies through support tools support and enhance creative collaboration in the business ecosystem [27]. 


\subsubsection{Ensuring Sustainability through Digital Technologies}

Until the introduction of the concept of sustainability, the central role of technologies in agriculture was the collection and analysis of data and the improvement of business processes in terms of saving time, simplifying work tasks, and reducing costs. So, these were individual solutions where the goal was to improve a certain aspect of the business. It has already been previously explained which business models have so far characterized agricultural activity.

However, the constant development of technologies related to the agricultural and food sector creates many opportunities that have not yet been fully explored [15], but there are indications that the development of solutions in the coming period will focus on the concept of sustainability. It is assumed that, in the coming period, the tools will be designed to monitor all phases in the value chain, used in several sectors [23].

For example, the implementation of a precision agricultural robotic laboratory for food production sustainability and food safety [28] will enable the production of food that has not been possible before, and, through 3D printing, will now be possible, and food safety will be automatically controlled in every part of the supply chain through sensors. Thus, agriculture must provide products that sustain the life of our growing global population in ways that are economically, environmentally, and socially sustainable and acceptable [4].

Based on data from existing business processes and available open data on weather, spatial or some other data, from an agronomic point of view focused on sustainability, improved algorithms will be built, such as algorithms for cultivation or food quality [14], and will enable transparency of chains, integration of agricultural and food production properties and environmental properties [29].

With the optimal use of sensors to improve sustainability and efficiency in terms of water management in agricultural systems, it is recommended to use sensors to determine water needs in crop production. These sensors can be used in fields to inform intelligent irrigation systems or placed on automated guided vehicles carrying out agricultural operations, thus promoting sustainable water management [19]. Such technologies, through added value [30], can help farmers to better manage water and reduce waste [31].

Not so long ago, with the advent of COVID-19, the agricultural sector suffered damage, especially to small farmers from rural areas who were unable to access direct markets and financial services in a pandemic situation. The emergence of COVID-19 has sparked a debate about adopting digital transformation in a global supply chain involving farmers. Blockchain technology can play a significant role in reducing intermediaries and enable small farmers to connect directly with customers and end users, and the possibility of corruption is reduced [10]. The concept of service-oriented architecture (SOA) can be achieved by the interoperability of data and web services by adopting international standards, semantically enabling data description [9].

The opportunities that technologies and new methods bring in the agricultural and food sector are still insufficiently explored, especially in terms of achieving sustainability [32]. Issues such as the circular economy, lean manufacturing, food production and safety, energy issues, food production, process management and modeling, waste reduction, resource and reuse issues, and the social aspect are just some that will characterize research in the context of Industry 4.0 relationships and sustainable development [33].

\subsubsection{Talent, Capability and Capacity Strengthening}

By applying knowledge management methods in agricultural business, decision-makers can manage planning instruments that can clearly show the level of complexity of agricultural processes, thus assessing its sustainability in relation to financial, material, and intangible resources [26].

The basic resource in agricultural activity is definitely data, and by using all the advanced possibilities of technology, through analysis, very important information can be obtained [34], important for saving resources or for timely response in agricultural processes. Based on the data, new algorithms or knowledge can be discovered that contribute to economic, environmental and social sustainability. 
The role of farmers and their responsibilities have been significantly expanded and they are expected to preserve nature and business prosperity, but also to be qualified managers who understand and respect our legal systems, including health and safety at work and environmental policies and guidelines. The production of fresh, tasty and healthy food is expected at the lowest possible price and with minimal impact on the environment. This means that farmers must have significant operational knowledge of finance and marketing, negotiations, but also technological knowledge to manage operations [4]. Competitive advantage is based on the intensive use of digital technologies [21], which contribute to sustainable growth and development.

Local capacity building and mentoring in the introduction of technologies play a very important role in fostering sustainability, especially because it is important to enabling the integration of local knowledge and ideas into global chains [35].

\subsubsection{Sustainable Innovation}

The development of practical technologies for education about innovation and support to agricultural businesses would not be possible without the support of policies that enable the realization of innovations [12]. The Digital Innovation Hubs should take an active role in raising awareness of digital technologies in agriculture and working to bridge the gap between producers and stakeholders by providing cross-sectoral networking opportunities, helping them find suitable business partners, collaboration models, funding instruments, and legal aid [23]. Innovation activities are highly dependent on policies and support from states [36,37].

Agricultural innovation systems should be more focused on a business mission that supports sustainability, should embrace technologies that can help them do so and should start to change [38]. The term Climate Smart Agriculture refers to an agricultural activity in which production processes are adapted to climate change, in parallel with environmental responsibility and food security responsibility for all. This can only be achieved through innovation technology, so the combination of innovation and smart technology is important in creating solutions for sustainable development [39].

Digital tools that enable the collaboration and communication of virtual agricultural support groups facilitate the transfer of information and potentially increase improved farm management practices. This form of cooperation strengthens the culture of the agricultural sector and contributes to the dissemination of knowledge [40].

\subsection{Benefits of Adopting Sustainability Driven by Agriculture}

The previous chapter presents guidelines for the future trend, sustainability driven by agriculture, through five key determinants of digital transformation. In the coming period, through the requirements defined by policies and set goals and planned actions, it is expected that in agriculture business activities, new business models will be adapted and adopted with the aim of sustainability, achieved through the determinants of digital transformation. Below are some of the possible business scenarios with an emphasis on expectations and the positive effects that are actually a potential result of sustainability driven by agriculture. Given the wide area of agricultural activity and its impact, it is very difficult to cover all segments, so there will be an emphasis on some key fields.

First of all, we need to start from the already mentioned main resource in agriculture, and that is data. The agricultural sector is a large data generator that is currently very poorly analyzed and applied. In the future, the combined application of generated agricultural data and open data on weather, spatial data, and other data is expected, which may result in advanced algorithms useful for decision making, automatic process control, and ensuring control and security in agricultural operations. For example, in livestock, or fruit and vegetable production, field monitoring data such as soil moisture, $\mathrm{pH}$, precipitation, growth rate, and maturity can help farmers determine the optimal way of fertilization, irrigation, or other business processes such as harvesting, protection, and more. The application of such advanced algorithms would contribute to saving water resources in irrigation, reduced use of pesticides, herbicides, and fertilizers, and saving time and costs. 
In addition, one of the very important segments that will be touched upon is the protection and assurance of soil biodiversity and soil sustainability. The future period will be marked by the development of smart solutions that will try to solve some of these problems. For example, the role of soil is of great importance in agricultural production and is an important active mediator of the process, which is the basis of life on earth. The development of a complex biomonitoring system to identify and remove sources of pollution in order to maintain maximum ecological potential is necessary and important for soil quality, but also for the conservation of biodiversity and human health [41]. Concerns about sustainability will accelerate the development of commercial solutions based on digital technologies aimed at improving the efficiency of biomass supply chains from precision cultivation to intelligent storage and logistics to optimal utilization by the end user [23]. Additionally, the use of biological pesticides will be increasingly involved in agricultural processes, allowing the preservation of good soil conditions and the reduction in its pollution index, with good consequences not only for human health but also for land use and economic efficiency [42].

In animal production, data on nutrition and nutritional values, breeding temperatures, and other production conditions are very important, and ultimately, the results on production quantities, revenues, and costs of breeding are also of importance. By applying the data and the algorithms defined on their basis, economic sustainability would be achieved through optimal production quantities and the lowest production costs. Furthermore, in order for these advanced algorithms to be developed and applied, infrastructure and digital technologies are needed, and expectations are certainly largely focused on the application of smart solutions in agricultural production. For example, in fruit, vegetable, and livestock production, Sensors, Internet of Things solutions, Big Data, Analytics, and Cloud technology combined with smart applications and software will play an important role. For example, sensors can easily detect moisture and this data can be stored on the application, which can automatically determine when irrigation is needed of a particular crop. In animal production, robotics, and automatic farm management, cyber-physical systems, data, and analysis will play an important role. In farms, an automatic feeding system can be defined and monitor the feeding of each animal based on smart chips.

Apart from the above, the strategic orientation, innovation, and organizational culture, capacity, customer centricity, and focus on all stakeholders, are not negligible. Through policies and goals in the future, the emphasis has already been placed on ensuring the concepts of sustainability through agriculture. However, all stakeholders are responsible for working to foster innovation, cooperation, and a good climate within the agricultural sector. Advanced tools and platforms for communication, exchange of experiences, publication, and exchange of data, innovation, and development of new products in agriculture can help. This can facilitate expansion into new markets, meeting the needs of markets where there is a deficit of certain agricultural products, and in the development of innovative products and the establishment of business cooperation, and this expansion can ultimately contribute to the development and growth of sustainability. For example, if there is a shortage of certain agricultural products on the market, producers can ensure economic sustainability by providing people products that may not be easily available to them. Furthermore, there are many specific agricultural products whose production can meet the needs of different markets. One of the examples is ducks. In the European market, duck meat is accepted in eating habits, while in the countries of the Eastern world, duck legs are usually used for food, and duck feathers for various production purposes. There are many such products whose production can simultaneously meet the needs of different markets and ensure sustainability, and through the application of platforms and connected value chains, this will be possible to achieve.

\section{Discussion and Future Work}

This article emphasized the digital transformation of agriculture that will enable the growth and development of economic, environmental and social sustainability. So far, the application of digital technologies has been aimed at ensuring the sustainability of the agricultural business, and the goals and policies of global economies have been focused on providing digital infrastructure and technologies 
and skills to advance the agricultural economy. It is important to mention that there are still large digital inequalities between developed urban areas and countries, in relation to the rural areas of that developing country as well as third world countries. Lack of financial resources and the adoption of technical components are just some of the problems faced by agricultural businesses. Sustainability driven by agriculture with its characteristics, through the determinants of digital transformation, will require great efforts in the development of new advanced opportunities, and then in the adoption of these solutions.

Global warming, climate change, weather disasters, and disruptions in economies are daily changing the way farms work. It is hard to expect that change will come quickly and easily. These are some of the problems the world has been struggling with for a very long time, but it seems unsuccessful given the events and consequences of the last few years. Policies need to be supportive, and efforts need to be focused on developing solutions that will seek to address precisely these challenges and problems. This will require a multidisciplinary approach and the efforts of experts from different fields, governments of all countries, and the cooperation of different industries, but also local producers.

Future research will focus on monitoring new digital trends in agriculture, with particular emphasis on advanced management capabilities for economic, environmental and social sustainability. Given the policies prepared by the European Commission for the period 2021-2027, it will be interesting to see whether there is progress in the concepts of sustainability led by agriculture, but also other industries.

In addition, future research will focus on the analysis of individual agricultural activities and their impact on sustainability concepts and will try to provide insight into the opportunities provided by each individual agricultural activity, in maintaining sustainability through the support of digital technologies. This will provide a scientific contribution in the form of recommendations for the development of technical solutions in agriculture that will support sustainability and at the same time enable the sustainability of the agricultural economy.

\section{Conclusions}

The digital transformation has changed all aspects of life and business and has resulted in new business initiatives such as new business models, and new products and services. This has affected the functioning and management of business processes in all sectors. Definitely, the benefits of applying digital technologies are not in question, and Big Data and Analytics, Internet of Things, Artificial Intelligence and Machine Learning, Blockchain, and Cyber-F systems are mostly applied. Improved forms of business supported by digital technologies have enabled the faster and easier performance of business tasks, saving time and money, flexibility and efficiency in business processes. So far, technologies have been viewed in the context of improving a company's business and increasing benefits for the company. However, global challenges such as climate change and global warming, drastic weather disasters, and unexpected disruptions are a growing problem of the economy, but also of private systems. This is precisely the reason for exploring new, advanced possibilities of digital technologies. In addition, the policies of global leaders highlight this issue and turn to create strategies for the development and growth of sustainability. The concept of sustainability emphasizes the goals related to the three main aspects, economic, environmental, and social sustainability. The agricultural sector has a particularly significant role in these three aspects, as activities that can directly affect them, in a positive or negative way. It was this thought that prompted the study of the impact of agriculture on sustainability and the analysis of the role of digital technologies in achieving sustainability in the agriculture context.

This research provides an overview of the current state of agricultural activity, the concept of sustainability, and digital transformation in the literature. An analysis of articles published in the Scopus and Web of Science databases has shown that this area is becoming increasingly interesting, especially in the last two years when the number of articles in this area has increased significantly. Definitely, the work and research of the scientific academic community and the efforts of global economies will be focused on discovering new digital solutions and business models that provide 
answers to sustainability problems, and this will represent a new generation of technological solutions. Agriculture will play a very important role in this process, as an activity closely related to the concepts of sustainability, and given its influence, it is expected to be a leader in positive change beneficial to society and the country.

Technical solutions in agriculture have so far been focused on the sustainability of the agricultural business, and the solutions usually linked some of the activities and were limited to individual business processes. In somewhat more complex systems, automated technology was applied, and the data collected were usually used for analysis, and then, based on them, some decisions were made. Agriculture as a business faces the challenges of climate change, drastic weather conditions, and significant changes in the production cycle (disruption), and, on the other hand, creates problems through gas emissions, environmental pollution through herbicides, pesticides, and fertilizers, and consumes significant resources. However, given the problems and challenges that, on the one hand, affect farmers, and, on the other hand, have a negative impact on sustainability, the development of new advanced digital solutions is expected to provide an answer to this.

Strategies are expected to be adapted to the sustainability of biodiversity and environmental protection, ensuring a sufficient amount of quality and healthy food, developing agricultural innovations, and harmonizing all other economic, environmental, and social goals. The emphasis will no longer be on customer needs, but on the needs of the entire ecosystem, which includes farmers and producers from other industries, policymakers and state governments, and all other stakeholders. The main resource will no longer be just data, but newly created advanced algorithms and knowledge with the help of which agricultural processes will be managed. Innovation and development of digital technologies will be focused on managing and addressing climate change and global warming, as well as responding to drastic weather changes and other disturbances in the economy.

Transformed agriculture should become an attractive activity that contributes to the harmonization and achievement of economic, environmental, and social sustainability goals. Agricultural business processes at all levels and between all stakeholders in the value chain are expected to be connected through advanced algorithms and smart digital technologies. Through such business, business scenarios should be realized, such as smart and optimal irrigation and protection, food control and safety, soil and diversity protection, smart management of farms, and animal production, all with achieved environmental, economic, and social sustainability goals. In addition, greater flexibility of agricultural holdings, a new approach to work and cooperation, and a strengthened culture should facilitate adaptation in the event of potential disruptions in economic, environmental, and social flows.

Funding: This research received no external funding.

Conflicts of Interest: The author declares no conflict of interest.

\section{References}

1. Shamin, A.; Frolova, O.; Makarychev, V.; Yashkova, N.; Kornilova, L.; Akimov, A. Digital transformation of agricultural industry. IOP Conf. Series Earth Environ. Sci. 2019, 346, 012029. [CrossRef]

2. Bogoviz, A.V.; Shkodinsky, S.V.; Skomoroshchenko, A.A.; Mishchenko, I.; Malyutina, T. Scenarios of Development of the Modern Global Economy with Various Growth Poles. In Book Growth Poles of the Global Economy: Emergence, Changes and Future Perspectives, Lecture Notes in the Networks and Systems; Popkova, E.G., Ed.; Springer: Cham, Switzerland, 2019; Volume 73, pp. 185-192.

3. Lammers, T.; Tomidei, L.; Regattieri, A. What Causes Companies to Transform Digitally? An Overview of Drivers for Australian Key Industries. In Proceedings of the 2018 Portland International Conference on Management of Engineering and Technology (PICMET), Honolulu, HI, USA, 19-23 August 2018.

4. Meinke, H. The role of modeling and systems thinking in contemporary agriculture. In Book Sustainable Food Supply Chains: Planning, Design, and Control through Interdisciplinary Methodologies; Accorsi, R., Manzini, R., Eds.; Elsevier: Bologna, Italy, 2019; pp. 39-47.

5. Nikolidakis, S.A.; Kandris, D.; Vergados, D.D.; Douligeris, C. Energy efficient automated control of irrigation in agriculture by using wireless sensor networks. Comput. Electron. Agric. 2015, 113, 154-163. [CrossRef] 
6. Bersani, C.; Ouammi, A.; Sacile, R.; Zero, E. Model Predictive Control of Smart Greenhouses as the Path towards Near Zero Energy Consumption. Energies 2020, 13, 3647. [CrossRef]

7. Herlitzius, T. Automation and Robotics-The Trend Towards Cyber Physical Systems in Agriculture Business. In Proceedings of the 9th AVL International Commercial Powertrain Conference 2017, Helmut-List-Halle, Austria, 10-11 May 2017; pp. 1-4. [CrossRef]

8. Yahya, N. Agricultural 4.0: Its Implementation Toward Future Sustainability. In Book Green Urea: Green Energy and Technology; Springer: Berlin/Heidelberg, Germany, 2018; pp. 125-145.

9. Lanucara, S.; Oggioni, A.; Di Fazio, S.; Modica, G. A Prototype of Service Oriented Architecture for Precision Agriculture. In Book Innovative Biosystems Engineering for Sustainable Agriculture, Forestry and Food Production, Lecture Notes in Civil Engineering; Coppola, A., Di Renzo, G.C., Altieri, G., D'Antonio, P., Eds.; Springer: Berlin/Heidelberg, Germany, 2020; Volume 67, pp. 765-774.

10. Quayson, M.; Bai, C.; Osei, V. Digital Inclusion for Resilient Post-COVID-19 Supply Chains: Smallholder Farmer Perspectives. IEEE Eng. Manag. Rev. 2020, 1. [CrossRef]

11. Knierima, A.; Kerneckerb, M.; Erdlec, K.; Krausb, K.; Borgesb, F.; Wurbsb, A. Smart farming technology innovations-Insights and reflections from the German Smart-AKIS hub. NJAS Wagening J. Life Sci. 2019, 90-91, 1-10. [CrossRef]

12. Bucci, G.; Bentivoglio, D.; Finco, A.; Belletti, M.; Bentivoglio, D. Exploring the impact of innovation adoption in agriculture: How and where Precision Agriculture Technologies can be suitable for the Italian farm system? IOP Conf. Series Earth Environ. Sci. 2019, 275, 012004. [CrossRef]

13. Sott, M.K.; Furstenau, L.B.; Kipper, L.M.; Giraldo, F.D.; Lopez-Robles, J.R.; Cobo, M.J.; Zahid, A.; Abbasi, Q.H.; Imran, M.A. Precision Techniques and Agriculture 4.0 Technologies to promote Sustainability in the Coffee Sector: State of the Art, Challenges and Future Trends. IEEE Access 2020, 8, 1. [CrossRef]

14. Valecce, G.; Strazzella, S.; Radesca, A.; Grieco, L.A. Solarfertigation: Internet of Things Architecture for Smart Agriculture. In Proceedings of the 2019 IEEE International Conference on Communications Workshops (ICC Workshops), Shanghai, China, 20-24 May 2019; pp. 1-6.

15. Trivelli, L.; Apicella, A.; Chiarello, F.; Rana, R.; Fantoni, G.; Tarabella, A. From precision agriculture to Industry 4.0.: Unveiling technological connections in the agrifood sector. Br. Food J. 2019, 121, 1730-1743. [CrossRef]

16. Arvanitis, K.G.; Symeonaki, E.G. Agriculture 4.0: The role of innovative smart technologies towards sustainable farm management. Open Agric. J. 2020, 14, 130-135. [CrossRef]

17. Tsolakis, N.; Aivazidou, E.; Srai, J.S. Sensor applications in agrifood systems: Current trends and opportunities for water stewardship. Climate 2019, 7, 44. [CrossRef]

18. Pihir, I.; Tomičić-Pupek, K.; Tomičić Furjan, M. Digital Transformation Insights and Trends. In Proceedings of the Central European Conference on Information and Intelligent Systems (CECIIS), Varaždin, Croatia, 19-21 September 2018; pp. 141-149.

19. Shinde, S.; Kimbahune, S.; Singh, D.; Deshpande, V.; Piplani, D.; Karthik, S. mKRISHI BAIF: Digital transformation in livestock services. In Proceedings of the India HCI 2014 Conference on Human Computer Interaction (IndiaHCI'14), New Delhi, India, 7-9 December 2014; pp. 148-153.

20. Yahya, N. Efficacy of Green Urea for Sustainable Agriculture. In Green Urea; Springer: Singapore, 2018; pp. 99-123.

21. Belaud, J.-P.; Prioux, N.; Vialle, C.; Sablayrolles, C. Big data for agri-food 4.0: Application to sustainability management for by-products supply chain. Comput. Ind. 2019, 111, 41-50. [CrossRef]

22. CAP Specific Objective: Ensuring Viable Farm Income (European Commission). Available online: https://ec.europa.eu/info/sites/info/files/food-farming-fisheries/key_policies/documents/cap_specific_ objectives_-_brief_1_-_ensuring_viable_farm_income.pdf (accessed on 10 September 2020).

23. Flak, J. Technologies for Sustainable Biomass Supply-Overview of Market Offering. Agronomy 2020, 10, 798. [CrossRef]

24. Ciruela-Lorenzo, A.M.; Obra, A.R.D.A.; Padilla-Meléndez, A.; Plaza-Angulo, J.J. Digitalization of Agri-Cooperatives in the Smart Agriculture Context. Proposal of a Digital Diagnosis Tool. Sustainability 2020, 12, 1325. [CrossRef]

25. Zahoor, S.; Abdul-Kader, W.; Zain, M.; Hussain, A.; Salman Habib, M. The Prospect of Smart-Remanufacturing in Automotive SMEs: A Case Study. In Proceedings of the International Conference on Industrial Engineering and Operations Management, Bangkok, Thailand, 5-7 March 2019; pp. 735-736. 
26. Mazzetto, F.; Gallo, R.; Riedl, M.; Sacco, P. Proposal of an ontological approach to design and analyse farm information systems to support Precision Agriculture techniques. IOP Conf. Series Earth Environ. Sci. 2019, 275, 012008. [CrossRef]

27. Wang, X.; Cao, D.; Chen, J.; Xiao, Z.; Daowd, A. AI and IoT based collaborative business ecosystem: A case in Chinese fish farming industry. Int. J. Technol. Manag. 2020, 82, 151-170.

28. Orsini, R.; Basili, D.; Belletti, M.; Bentivoglio, D.; Bozzi, C.A.; Chiappini, S.; Conti, C.; Galli, A.; Giorgini, E.; Fiorentini, M.; et al. Setting of a precision farming robotic laboratory for cropping system sustainability and food safety and security: Preliminary results. IOP Conf. Series Earth Environ. Sci. 2019, 275, 012021. [CrossRef]

29. Giannoccaro, N.I.; Persico, G.; Strazzella, S.; Lay-Ekuakille, A.; Visconti, P. A System for Optimizing Fertilizer Dosing in Innovative Smart Fertigation Pipelines: Modeling, Construction, Testing and Control. Int. J. Precis. Eng. Manuf. 2020, 1-16. [CrossRef]

30. Darko, R.O.; Liu, J.; Yuan, S.; Sam-Amoah, L.K.; Yan, H. Irrigated agriculture for food self-sufficiency in the sub-Saharan African region. Int. J. Agric. Biol. Eng. 2020, 13, 1-12. [CrossRef]

31. Bentley, J.W.; Van Mele, P.; Barres, N.F.; Okry, F.; Wanvoeke, J. Smallholders download and share videos from the Internet to learn about sustainable agriculture. Int. J. Agric. Sustain. 2019, 17, 92-107. [CrossRef]

32. Lezoche, M.; Hernandez, J.E.; Díaz, M.D.M.E.A.; Panetto, H.; Kacprzyk, J. Agri-food 4.0: A survey of the supply chains and technologies for the future agriculture. Comput. Ind. 2020, 117, 103187. [CrossRef]

33. Smetana, S.M.; Aganovic, K.; Heinz, V. Food Supply Chains as Cyber-Physical Systems: A Path for More Sustainable Personalized Nutrition. Food Eng. Rev. 2020, 1-12. [CrossRef]

34. Davies, F.T.; Garrett, B. Technology for Sustainable Urban Food Ecosystems in the Developing World: Strengthening the Nexus of Food-Water-Energy-Nutrition. Front. Sustain. Food Syst. 2018, 2, 1-11. [CrossRef]

35. Kheyfets, B.A.; Chernova, V.Y. Sustainable agriculture in Russia: Research on the dynamics of innovation activity and labor productivity. Entrep. Sustain. Issues 2019, 7, 814-824. [CrossRef]

36. Furstenau, L.B.; Sott, M.K.; Kipper, L.M.; Machado, E.L.; Lopez-Robles, J.R.; Dohan, M.S.; Martin, M.J.C.; Zahid, A.; Abbasi, Q.H.; Imran, M.A. Link between sustainability and industry 4.0: Trends, challenges and new perspectives. IEEE Access 2020, 8, 1. [CrossRef]

37. Zhou, Y.; Xu, L.; Shaikh, G.M. Evaluating and Prioritizing the Green Supply Chain Management Practices in Pakistan: Based on Delphi and Fuzzy AHP Approach. Symmetry 2019, 11, 1346. [CrossRef]

38. Klerkx, L.; Rose, D. Dealing with the game-changing technologies of Agriculture 4.0: How do we manage diversity and responsibility in food system transition pathways? Glob. Food Secur. 2020, 24, 100347. [CrossRef]

39. Brohm, K.A.; Klein, S. The Concept of Climate Smart Agriculture-A Classification in Sustainable Theories. Int. J. Qual. Res. 2019, 14, 291-302. [CrossRef]

40. Mushtaq, S.; Reardon-Smith, K.; Cliffe, N.; Ostini, J.; Farley, H.; Doyle, J. Can Digital Discussion Support Tools Provide Cost-Effective Options for Agricultural Extension Services? Inf. Technol. Int. Dev. 2017, 13, 52-68.

41. Butnariu, M. Markers, Indicators of Soil Pollution. In Book Environmental Indicators; Armon, R.H., Hänninen, O., Eds.; Springer: Dordrecht, The Netherlands, 2014; pp. 343-364.

42. Butu, M.; Stef, R.; Grozea, I.; Corneanu, M.; Butnariu, M. Biopesticides: Clean and Viable Technology for Healthy Environment. In Book Bioremediation and Biotechnology, Sustainable Approaches to Pollution Degradation; Springer: Berlin/Heidelberg, Germany, 2020; pp. 107-151.

Publisher's Note: MDPI stays neutral with regard to jurisdictional claims in published maps and institutional affiliations.

(C) 2020 by the author. Licensee MDPI, Basel, Switzerland. This article is an open access article distributed under the terms and conditions of the Creative Commons Attribution (CC BY) license (http://creativecommons.org/licenses/by/4.0/). 